Revista Geográfica Digital. IGUNNE. Facultad de Humanidades. UNNE. Año 12. № 24. Julio - Diciembre 2015. ISSN 1668-5180 Resistencia, Chaco

\title{
CONTRIBUCIÓN DE LAS ENCUESTAS DE MOVILIDAD DOMICILIARIA \\ AL ANÁLISIS DE LA MOVILIDAD URBANA. \\ EOD APLICADA AL GRAN CORRIENTES.
}

\section{CONTRIBUTION OF THE SURVEYS OF HOME MOBILITY \\ TO THE ANALYSIS OF URBAN MOBILITY. ODS APPLIED TO THE GREAT CORRIENTES.}

\author{
Arq. Silvina López \\ silvina_lopez@hotmail.com \\ Ing. Guillermo Antonio Arce \\ gar_arce@yahoo.com.ar
}

Centro de Geociencias Aplicadas - UNNE

\section{Resumen}

El Gran Corrientes conforma un sistema urbano integrado por la ciudad de Corrientes, capital de la provincia, y un conjunto de asentamientos urbanos y rurales con gran dependencia funcional y económica, y sujeto a fuertes presiones provocadas por los procesos de expansión de la misma.

Una de las problemáticas que se ha identificado en trabajos previos sobre el área, y que está directamente asociada al tipo de expansión urbana extendida y discontinua, es la de la movilidad urbana. Por este motivo, la publicación reciente de los resultados de la Encuesta OrigenDestino aplicada al Gran Corrientes en 2013, se presentó como una oportunidad para analizar datos relacionados con la movilidad en el área metropolitana en estudio.

El trabajo que se presenta, es un análisis que contrasta los aspectos metodológicos y los resultados del estudio, con las características de la ciudad y su territorio, identificando potencialidades y limitaciones de este tipo de herramienta, y reflexionando a partir de la conceptualización planteada como marco de referencia.

Palabras claves: movilidad urbana, encuesta Origen-Destino, Gran Corrientes.

\section{Abstract}

The "Gran Corrientes" conforms an urban system composed of Corrientes city, capital of the province, and a set of urban and rural settlements with great functional and economic dependence. This system is subject to strong pressures of processes of expansion of the Capital.

Publicado en formato digital: Arq. Silvina López; Ing. Guillermo Antonio Arce. CONTRIBUCION DE LAS ENCUESTAS DE MOVILIDAD DOMICILIARIA AL ANALISIS DE LA MOVILIDAD URBANA. EOD APLICADA AL GRAN CORRIENTES.. Revista Geográfica Digital. IGUNNE. Facultad de Humanidades. UNNE. Año 12. № 24. Julio - Diciembre 2015. ISSN 1668 - 5180. Resistencia, Chaco. En: http://hum.unne.edu.ar/revistas/geoweb/default.htm 
Revista Geográfica Digital. IGUNNE. Facultad de Humanidades. UNNE. Año 12. № 24. Julio - Diciembre 2015. ISSN 1668-5180 Resistencia, Chaco

The urban mobility is one of the problems that have been identified in previous works on the area, which is directly associated to the type of extended and discontinuous urban expansion. For this reason, the recent publication of the results of the Origin-Destination Survey applied to the Great Corrientes in 2013 , has represented as an opportunity to analyze data related to mobility in the metropolitan area under study.

This work is an analysis that contrast methodological aspects and results of the study with the characteristics of the city and its territory, identifying potentials and limitations of this type of tool and pondering from the conceptualization raised as a framework of reference.

Keywords: urban mobility, origin-destination survey, Great Corrientes

\section{Introducción}

El Gran Corrientes conforma un sistema urbano integrado por la ciudad de Corrientes, capital de la provincia, y un conjunto de asentamientos urbanos y rurales con gran dependencia funcional y económica, y sujeto a fuertes presiones provocadas por los procesos de expansión de la misma.

Esta área ha presentado en los últimos años procesos de ocupación del espacio caracterizados por la expansión extendida, discontinua, y con una fuerte presión sobre el sistema natural. Se ha acentuado además, la tendencia al desplazamiento de población de nivel socioeconómico medio-alto hacia el área periurbana y rural, provocando el consumo de tierras productivas que abastecen a la ciudad, y por otra parte, la subutilización de sectores centrales tradicionalmente ocupados por esos estratos sociales.

Una de las problemáticas que se ha identificado en trabajos previos realizados, y que está directamente asociada a este tipo de expansión, es la de la movilidad urbana. Considerando el vínculo indisoluble entre las problemáticas urbanas y el territorio, no es posible separar la problemática de la movilidad de la conformación del territorio de la ciudad, de su estructura, su infraestructura, y la distribución de los equipamientos y servicios.

En ese sentido es importante considerar la visión que propone el Plan Estratégico Territorial de la Argentina, que relaciona la movilidad con las políticas urbanas, "...la movilidad se propone como una mirada complementaria para analizar las dinámicas y los problemas socio-territoriales, como una puerta de entrada diferente para reconstruir el funcionamiento de la sociedad en el ámbito urbano..." (PET, 2011)

En este marco, la publicación reciente de los resultados de la Encuesta de Movilidad Domiciliaria Origen - Destino para las Áreas Metropolitanas de las ciudades de Resistencia Corrientes realizada en el año 2013, se presentó como una oportunidad para incorporar una visión complementaria al análisis de las problemáticas socio-territoriales del área en estudio.

Publicado en formato digital: Arq. Silvina López; Ing. Guillermo Antonio Arce. CONTRIBUCION DE LAS ENCUESTAS DE MOVILIDAD DOMICILIARIA AL ANALISIS DE LA MOVILIDAD URBANA. EOD APLICADA AL GRAN CORRIENTES.. Revista Geográfica Digital. IGUNNE. Facultad de Humanidades. UNNE. Año 12. № 24. Julio - Diciembre 2015. ISSN 1668 - 5180. Resistencia, Chaco. En: http://hum.unne.edu.ar/revistas/geoweb/default.htm 


\section{Conceptualización de la movilidad urbana}

Gutiérrez, entiende a la movilidad como una práctica social de viaje, por su manifestación en el territorio, por la frecuencia en su realización, traducida en comportamientos de viaje, y por una manifestación reiterada de comportamientos que definen un patrón de desplazamiento en un contexto socio territorial y temporalmente determinado. (Gutierrez, 2009)

"...Se entiende, entonces, por movilidad una práctica social de viaje que conjuga deseos y necesidades de desplazamiento (que en conjunto pueden definirse como requerimientos de movilidad) y capacidades de satisfacerlos... Las prácticas de viaje hacen a la manera en que se apropia el territorio, y trascienden la oferta de "equipamientos" de transporte (individual o colectivo, redes o servicios). Los cambios aparejados por nuevos patrones de acumulación cambian la localización de las actividades y la población, y también la forma de "uso" del territorio". (Gutierrez, 2009).

En relación a la movilidad de las personas, Vasconcellos identifica los principales factores que interfieren en la misma, "En primer lugar, la movilidad aumenta con el aumento del ingreso. En segundo lugar, varía conforme a las características económicas y sociales de las personas.(...). Personas con un nivel educacional más alto viajan más que las demás y adultos con trabajo regular se desplazan más que los que tienen una ocupación inestable. A las diferencias en la movilidad se agregan hábitos distintivos de cada grupo socioeconómico en el uso del transporte" (Vasconcellos, 1996).

Coincidentemente, dice Seguí Pons que "...la demanda de desplazamientos crece a medida que se incrementa el nivel de vida, las tasas de motorización y el tiempo de ocio.". (Seguí Pons, 1991)

Vasconcellos sostiene que la movilidad se relaciona directamente con las características de la ciudad, "...para comprender qué desplazamientos se realizan y qué tipo de transporte es necesario para llevarlos a cabo, es necesario comprender cómo está estructurada la ciudad, cómo se distribuyen las actividades en su espacio, así como cuáles son los factores de mayor influencia en la movilidad de las personas y en la elección de los modos de transporte." (Vasconcellos, 1996)

En relación con los estudios de movilidad y transporte, dice Pizarro que "La ausencia de información sistemática del sistema de transporte es la norma en la mayoría de las ciudades latinoamericanas. Lo que conlleva a la toma de decisiones de planificación con poco sustento científico, a la ausencia de monitoreo del comportamiento del sistema en el tiempo y al limitado conocimiento de los resultados de las políticas implementadas." (Pizarro, 2013)

Entre los estudios que se basan en el dimensionamiento de la oferta del transporte en función de la demanda, se encuentra la Encuesta de Origen y Destino. La EOD es una herramienta que provee información de los modos de transporte y rutas entre las celdas definidas por un modelo teórico, en el que el área urbana se divide en zonas de tráfico en las cuales se asume una conducta homogénea en materia de transporte.

Publicado en formato digital: Arq. Silvina López; Ing. Guillermo Antonio Arce. CONTRIBUCION DE LAS ENCUESTAS DE MOVILIDAD DOMICILIARIA AL ANALISIS DE LA MOVILIDAD URBANA. EOD APLICADA AL GRAN CORRIENTES.. Revista Geográfica Digital. IGUNNE. Facultad de Humanidades. UNNE. Año 12. № 24. Julio - Diciembre 2015. ISSN 1668 - 5180. Resistencia, Chaco. En: http://hum.unne.edu.ar/revistas/geoweb/default.htm 
Revista Geográfica Digital. IGUNNE. Facultad de Humanidades. UNNE. Año 12. № 24. Julio - Diciembre 2015. ISSN 1668-5180 Resistencia, Chaco

En relación con los modelos, según Seguí Pons, el criterio de zonificación se realiza de acuerdo con el nivel de planificación y el número de zonas establecido, y de él depende la precisión de los resultados. (Seguí Pons, 1991)

Una de las características mas importantes de la movilidad urbana es que no es tan solo espacial sino también temporal, en ese sentido "Ias encuestas de OD permiten obtener información acerca del tiempo medio según motivos, según motivos y nivel de renta, tiempo medio según modos, tiempo medio según modos y motivos, según modos y corona de residencia, y relacionar el tiempo del recorrido con la longitud de los viajes." (Gutierrez Puebla, 1990).

\section{Análisis de la aplicación de la Encuesta Origen Destino}

Con el enfoque previamente planteado, en este trabajo se realiza el análisis de la EOD revisando sus objetivos, los criterios empleados en la definición de los dominios que fueron delimitados para el estudio, y los resultados obtenidos, contrastando con las características del territorio del Gran Corrientes.

Analizando el tipo de información que permite obtener la EOD, y los datos posibles de construir a partir de la misma, se plantean las potencialidades y limitaciones que se pudieron observar de este estudio en particular y de las EOD en general.

Luego de considerar las cuestiones metodológicas, y revisar y graficar la información resultante de la EOD contrastándola con las características de la ciudad y su territorio, se concluye con algunas reflexiones intentando relacionar el análisis realizado con la conceptualización de la movilidad urbana planteada inicialmente.

\section{Objetivos de la aplicación de la EOD}

El estudio fue realizado en el año 2013, en el marco del Proyecto de Transporte Urbano en Áreas Metropolitanas de la Argentina, con el objetivo de determinar el modo en que se realizan los desplazamientos y los motivos de movilización habitual de la población residente en las áreas metropolitanas de Resistencia y Corrientes.

Los Objetivos específicos que se propuso la EOD fueron:

a) Identificar la estructura y los principales componentes y patrones de movilidad en las áreas metropolitanas de Resistencia y Corrientes;

b) Determinar el número y motivos de los viajes, medios de transporte empleados, origen y destino de los traslados, horarios de mayor demanda, duración y costos;

c) Establecer diferencias en los patrones de movilidad en términos de género, edad, ocupación, ingreso, lugar de residencia, nivel educativo y otras variables relevantes a la planificación del transporte en áreas urbanas;

d) Establecer la proporción de los gastos totales en transporte con respecto al gasto total mensual de los hogares y con respecto a su nivel de ingresos;

Publicado en formato digital: Arq. Silvina López; Ing. Guillermo Antonio Arce. CONTRIBUCION DE LAS ENCUESTAS DE MOVILIDAD DOMICILIARIA AL ANALISIS DE LA MOVILIDAD URBANA. EOD APLICADA AL GRAN CORRIENTES.. Revista Geográfica Digital. IGUNNE. Facultad de Humanidades. UNNE. Año 12. № 24. Julio - Diciembre 2015. ISSN 1668 - 5180. Resistencia, Chaco. En: http://hum.unne.edu.ar/revistas/geoweb/default.htm 
Revista Geográfica Digital. IGUNNE. Facultad de Humanidades. UNNE. Año 12. № 24. Julio - Diciembre 2015. ISSN 1668-5180 Resistencia, Chaco

e) Establecer la relación entre variables de transporte y bienestar, principalmente en los sectores de menores niveles de ingreso y mayor incidencia de la pobreza;

f) Conocer la percepción y opinión de los ciudadanos sobre el funcionamiento de los servicios de transporte público existentes en la actualidad;

g) Generar información que sirva como insumo esencial para la elaboración de modelos de transporte, importante herramienta de planificación del transporte.

Para la realización de la EOD, se consideró viaje a cada movimiento o desplazamiento en un sentido entre un punto de origen y otro de destino a lo largo de un recorrido por un determinado motivo, dado generalmente por la actividad a realizar en el destino, realizado por cada integrante del hogar residente en esa vivienda.

Se consideró viaje a todo desplazamiento mayor a 400 metros, realizado por un motivo determinado entre un origen y un destino. Los viajes son realizados a pie o utilizando medios de transporte (automóvil, colectivo, bicicleta, etc.), y el tiempo de referencia para los viajes fue de lunes a viernes hábiles.

Para la delimitación de los dominios, el estudio estableció las características definidas para cada uno de ellos:

- el Macrocentro, se define como el "área predominantemente residencial compartida con espacios de comercios y servicios públicos y personales",

- el Microcentro es la "parte del macrocentro con clara predominancia de actividades económicas y de servicios públicos y privados",

- el Resto de la ciudad es el "área del ejido urbano que no incluye la zona del macrocentro".

- el Conurbano está conformado por los "municipios que colindan y tienen una relación directa (económica, laboral, educativa) con las ciudades en estudio".

\section{Dominios definidos para el Gran Corrientes}

El hecho de realizar una zonificación para el estudio, implica como supuesto subyacente la idea de homogenización de determinadas áreas de la ciudad, y de que la movilidad se trata de flujos entre ellas.

La primera observación es la falta de una visión conjunta del binomio Corrientes Resistencia que está planteado en el estudio, pero no se plasma en su desarrollo, realizando un tratamiento separado de las ciudades.

En el caso del Gran Corrientes se definieron solamente dos dominios de análisis, el "Macrocentro" de la Ciudad y el "Resto de Corrientes", no utilizando las categorías de "Microcentro" y "Conurbano" previstas en el estudio.

En relación con el dominio "Macrocentro" de Corrientes delimitado por la EOD, el informe final explica que se efectuó sobre la Cartografía Censal (2001) a partir de la información disponible,

Publicado en formato digital: Arq. Silvina López; Ing. Guillermo Antonio Arce. CONTRIBUCION DE LAS ENCUESTAS DE MOVILIDAD DOMICILIARIA AL ANALISIS DE LA MOVILIDAD URBANA. EOD APLICADA AL GRAN CORRIENTES.. Revista Geográfica Digital. IGUNNE. Facultad de Humanidades. UNNE. Año 12. № 24. Julio - Diciembre 2015. ISSN 1668 - 5180. Resistencia, Chaco. En: http://hum.unne.edu.ar/revistas/geoweb/default.htm 
Revista Geográfica Digital. IGUNNE. Facultad de Humanidades. UNNE. Año 12. № 24. Julio - Diciembre 2015. ISSN 1668-5180 Resistencia, Chaco

incluyendo las normativas de Catastro y Planeamiento Urbano Municipal. Es observable que la delimitación del dominio crea una serie de discontinuidades en la definición de sus límites, excluyendo sectores con características similares y alta homogeneidad con el "Macrocentro". (Imagen №1)

\section{Imagen №1 : Dominios definidos para Gran Corrientes}

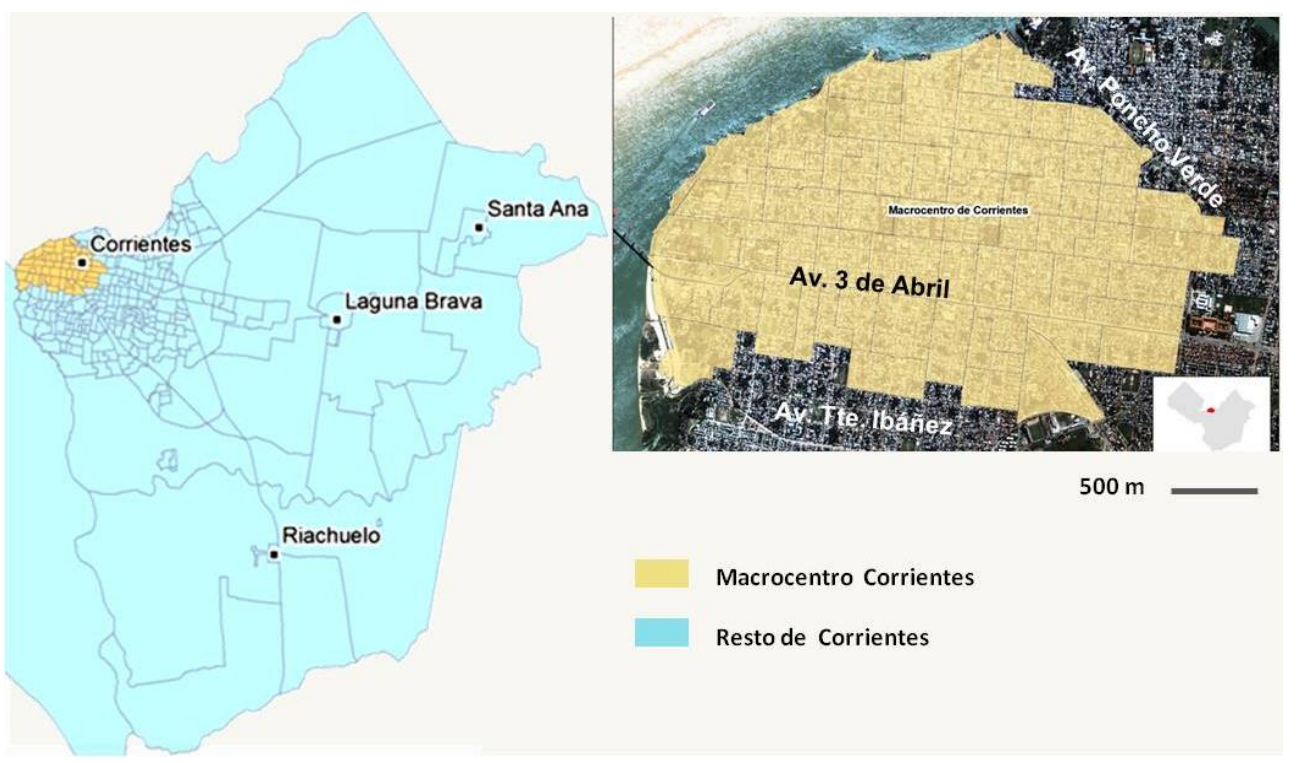

Fuente: Informe Final EOD. 2013

Por otra parte, en un único dominio "Resto Gran Corrientes", el estudio incluye el área urbana de Corrientes (excepto Macrocentro), las zonas rurales, y los municipios colindantes de Riachuelo y Santa Ana.

Al respecto, no quedan claros los criterios utilizados para esta delimitación, ni los motivos por los cuales se decide no utilizar la categoría "Conurbano" en este caso. Si bien entre la ciudad de Corrientes y las localidades incluidas en el estudio no se produce un continuo urbano, sino que aparecen áreas periurbanas y rurales intermedias, se cumple la situación de "municipios que colindan y tienen una relación directa económica, laboral, educativa", tal como lo plantea la definición de "Conurbano" que el estudio establece.

La delimitación adoptada hace que entre los Radios urbanos y rurales seleccionados como puntos de muestra (PM) del dominio "Resto de Corrientes", se den marcadas diferencias en densidad poblacional y edilicia, en la trama urbana, servicios, equipamiento e infraestructura. (Imagen №2).

Publicado en formato digital: Arq. Silvina López; Ing. Guillermo Antonio Arce. CONTRIBUCION DE LAS ENCUESTAS DE MOVILIDAD DOMICILIARIA AL ANALISIS DE LA MOVILIDAD URBANA. EOD APLICADA AL GRAN CORRIENTES.. Revista Geográfica Digital. IGUNNE. Facultad de Humanidades. UNNE. Año 12. № 24. Julio - Diciembre 2015. ISSN 1668 - 5180. Resistencia, Chaco. En: http://hum.unne.edu.ar/revistas/geoweb/default.htm 
Revista Geográfica Digital. IGUNNE. Facultad de Humanidades. UNNE. Año 12. № 24. Julio - Diciembre 2015. ISSN 1668-5180 Resistencia, Chaco

La encuesta de movilidad informa que para la determinación de la distintas zonificaciones se mantuvieron entrevistas con funcionarios municipales, sin embargo, no explica cómo se realizó la delimitación ni los criterios que se utilizaron para determinar la homogeneidad de cada zona.

Esto resulta muy relevante pues, siguiendo a Seguí Pons, de los criterios de zonificación - los cuales deben tener en cuenta el nivel de planificación y el número de zonas establecido - depende la precisión de los resultados.

Imagen №2: Dominios delimitados y Radios seleccionados para los PM de Corrientes
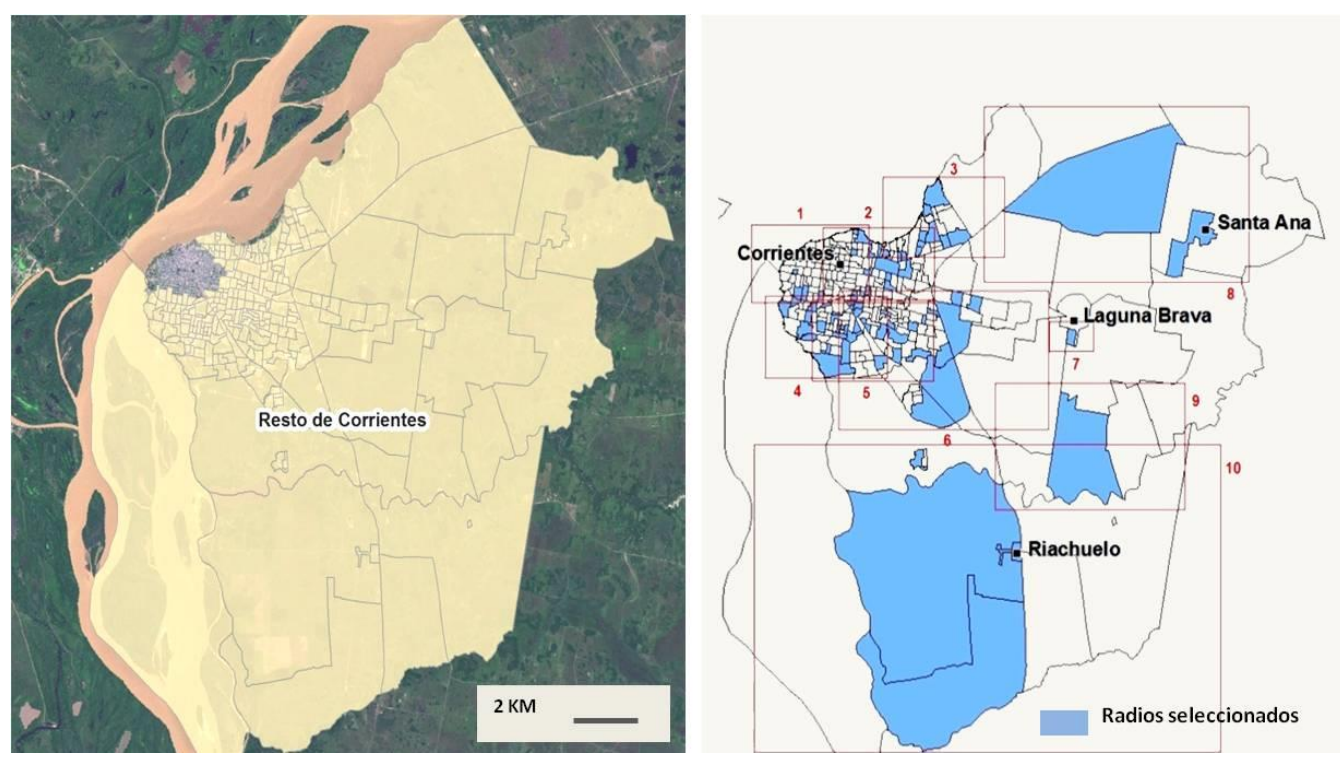

Fuente: Informe Final. EOD. 2013

\section{El territorio del Gran Corrientes}

Considerando que no es posible separar la problemática de la ciudad con la de los servicios y de la infraestructura de transporte, es necesario conocer algunas características generales del Gran Corrientes para revisar los criterios aplicados en la delimitación de los dominios para el estudio.

El Gran Corrientes conforma uno de los núcleos estructurantes del territorio nacional y se encuentra dentro de uno de los corredores importantes del país (PET, 2008), y fue categorizado como Nodo Regional de tercer nivel de jerarquía en el Sistema Urbano Nacional por el Programa Argentina Urbana del PET (PET, 2011).

En 2001 el INDEC consideraba Gran Corrientes a la ciudad de Corrientes y al Barrio Esperanza, el cual se encontraba en una zona en litigio entre los municipios de Corrientes y Riachuelo. El B Esperanza fue censado en 2001 como localidad separada a la ciudad de Corrientes,

Publicado en formato digital: Arq. Silvina López; Ing. Guillermo Antonio Arce. CONTRIBUCION DE LAS ENCUESTAS DE MOVILIDAD DOMICILIARIA AL ANALISIS DE LA MOVILIDAD URBANA. EOD APLICADA AL GRAN CORRIENTES.. Revista Geográfica Digital. IGUNNE. Facultad de Humanidades. UNNE. Año 12. № 24. Julio - Diciembre 2015. ISSN 1668 - 5180. Resistencia, Chaco. En: http://hum.unne.edu.ar/revistas/geoweb/default.htm 
Revista Geográfica Digital. IGUNNE. Facultad de Humanidades. UNNE. Año 12. № 24. Julio - Diciembre 2015. ISSN 1668-5180 Resistencia, Chaco

con una población de 2.236 habitantes (INDEC, 2001), mientras que en el censo de 2010 fue incluido dentro de la ciudad de Corrientes. (Tabla $\mathrm{N}^{\circ} 1$ )

En los últimos años el término Gran Corrientes comenzó a utilizarse con mayor frecuencia, designando al aglomerado urbano formado como consecuencia de la expansión de la ciudad de Corrientes y la estrecha relación funcional con los municipios aledaños de Riachuelo y Santa Ana.

El área considerada para la definición de Dominios del Gran Corrientes en el estudio de EOD, incluye los municipios de Capital, Riachuelo y Santa Ana. Esta área representa un poco más de 359 mil habitantes, siendo el Municipio Capital el de mayor peso poblacional, concentrando el $98 \%$ de la población de la misma.

El municipio Capital tiene más del 98\% de población urbana entre sus dos localidades censales, ciudad de Corrientes y Laguna Brava. Esta ultima oficialmente no considerada por el INDEC como parte del Gran Corrientes, aunque si por otros entes oficiales.

Riachuelo y Santa Ana, municipios colindantes a Capital, tienen escasa población (menos de 5 mil habitantes) y son municipios rurales, ya que sus localidades no alcanzan los 2 mil habitantes. Tienen un alto porcentaje de población en parajes y población dispersa en el área rural, un 33\% en el primer caso y un $41 \%$ en el segundo. (Tabla $\mathrm{N}^{\circ} 1$ )

Tabla N¹: Población total, urbana y rural por Municipio y localidad 2010

\begin{tabular}{|l|r|r|r|r|}
\hline Municipios y localidades & Población total & \% urbana & Población urbana & Población rural \\
\hline Municipio Capital (1) & $\mathbf{3 5 2 . 3 7 4}$ & $98,3 \%$ & $\mathbf{3 4 6 . 3 3 4}$ & $\mathbf{6 . 0 4 0}$ \\
\hline Localidad Corrientes & 343.020 & $100,0 \%$ & 343.020 & - \\
\hline Localidad Laguna Brava & 3.314 & $100,0 \%$ & 3.314 & - \\
\hline Municipio Riachuelo (2) & $\mathbf{4 . 2 1 8}$ & $0,0 \%$ & - & $\mathbf{4 . 2 1 8}$ \\
\hline Localidad Riachuelo & 1.965 & $0,0 \%$ & - & 1.965 \\
\hline Localidad San Cayetano & 872 & $0,0 \%$ & - & 872 \\
\hline Municipio Santa Ana (3) & $\mathbf{3 . 2 4 8}$ & $0,0 \%$ & - & 3.248 \\
\hline Localidad Santa Ana & 1.906 & $0,0 \%$ & - & 1.906 \\
\hline Total área (1+2+3) & $\mathbf{3 5 9 . 8 4 0}$ & $96,2 \%$ & $\mathbf{3 4 6 . 3 3 4}$ & $\mathbf{1 3 . 5 0 6}$ \\
\hline TOTAL PROVINCIA & 992.595 & $92,3 \%$ & 822.224 & 170.371 \\
\hline
\end{tabular}

Fuente: elaboración propia en base a Censo 2010 (INDEC, 2010)

La ciudad de Corrientes, capital de la Provincia, con 343 mil habitantes (INDEC, 2010), concentra el $35 \%$ de la población de la provincia. En la Capital predominan las actividades vinculadas con la prestación de servicios a escala de la ciudad y de un entorno regional, con importante participación económica de la administración pública y los servicios sociales.

Publicado en formato digital: Arq. Silvina López; Ing. Guillermo Antonio Arce. CONTRIBUCION DE LAS ENCUESTAS DE MOVILIDAD DOMICILIARIA AL ANALISIS DE LA MOVILIDAD URBANA. EOD APLICADA AL GRAN CORRIENTES.. Revista Geográfica Digital. IGUNNE. Facultad de Humanidades. UNNE. Año 12. № 24. Julio - Diciembre 2015. ISSN 1668 - 5180. Resistencia, Chaco. En: http://hum.unne.edu.ar/revistas/geoweb/default.htm 
Revista Geográfica Digital. IGUNNE. Facultad de Humanidades. UNNE. Año 12. № 24. Julio - Diciembre 2015. ISSN 1668-5180 Resistencia, Chaco

El Área Urbana tiene una superficie de 5.898 has, aproximadamente un $20 \%$ de la superficie del ejido municipal, con baja densidad de ocupación (55,5 habitantes por hectárea en promedio), y muy bajo nivel de consolidación de infraestructuras y servicios.

En el área central, emplazada en el ángulo NO de la ciudad se localiza la mayor parte de la actividad comercial, financiera, administrativa, de salud, educativa, recreativa y cultural, con los problemas derivados de la concentración excesiva de las mismas en una superficie relativamente reducida.

Por otra parte, presenta una periferia muy extensa con grandes vacíos urbanos, déficits de infraestructura y servicios urbanos, y serios problemas de conectividad, y en los últimos años se está acelerando el proceso de localización de desarrollos residenciales en las áreas periurbanas y rurales del municipio, y en las vías de vinculación con Riachuelo y Santa Ana de los Guácaras.

En el municipio de Riachuelo, la localidad de Riachuelo localizada a $18 \mathrm{~km}$ de la ciudad de Corrientes, tiene un carácter principalmente administrativo, con desarrollo de actividades vinculadas al comercio minorista. En la localidad de San Cayetano y los Parajes rurales que se localizan a la vera de las Rutas tanto nacionales como provinciales, se desarrolla actividad ganadera de pequeña escala, huertas para autoconsumo y excedentes para comercialización principalmente en ferias francas en la ciudad de Corrientes.

La localidad de Santa Ana ubicada a $15 \mathrm{~km}$ de la ciudad de Corrientes es una localidad con valor patrimonial, histórico y turístico. En los parajes rurales predominan las casas quintas con vivienda y chacras con producción de autoconsumo, y en los predios de mayor superficie, la ganadería bovina extensiva es la actividad más importante. En los últimos años se ha incrementado el número de emprendimientos inmobiliarios destinados a urbanizaciones residenciales, la mayoría con el formato de barrios cerrados, sobre todo en los ejes de vinculación con la ciudad de Corrientes.

\section{Observaciones a la delimitación de los Dominios}

Con respecto a los criterios adoptados en la delimitación de los dominios, cabe considerar la zonificación en Distritos que realiza el Código de Planeamiento de la Ciudad de Corrientes (CPU).

La definición que realiza el estudio de EOD del dominio "Macrocentro" coincide con las características de los distritos Centrales, Comerciales y Residenciales. Dichos distritos están localizados en el sector urbano comprendido entre las avenidas Costanera, Poncho Verde, Artigas y Tte. Ibañez.

Si bien el criterio de zonificación de la EOD deja afuera algunas porciones de este sector, abarca en un porcentaje representativo, el área de la ciudad en que se concentran las actividades administrativas, financieras, comerciales, educativas, culturales y de servicios.

Publicado en formato digital: Arq. Silvina López; Ing. Guillermo Antonio Arce. CONTRIBUCION DE LAS ENCUESTAS DE MOVILIDAD DOMICILIARIA AL ANALISIS DE LA MOVILIDAD URBANA. EOD APLICADA AL GRAN CORRIENTES.. Revista Geográfica Digital. IGUNNE. Facultad de Humanidades. UNNE. Año 12. № 24. Julio - Diciembre 2015. ISSN 1668 - 5180. Resistencia, Chaco. En: http://hum.unne.edu.ar/revistas/geoweb/default.htm 
Revista Geográfica Digital. IGUNNE. Facultad de Humanidades. UNNE. Año 12. № 24. Julio - Diciembre 2015. ISSN 1668-5180 Resistencia, Chaco

El Código de Planeamiento delimita además, el área urbana de la ciudad (AU). El tipo de ocupación y las densidades de población dentro de la misma, muestran el territorio que debería ser considerado como ejido urbano, identificado como "Resto de Corrientes", según las propias definiciones de la metodología aplicada a la EOD.

Por otra parte, atendiendo a la conformación de la red vial de la ciudad, se puede observar que en área definida como "Macrocentro" todas las vías de circulación vehicular se hallan pavimentadas.

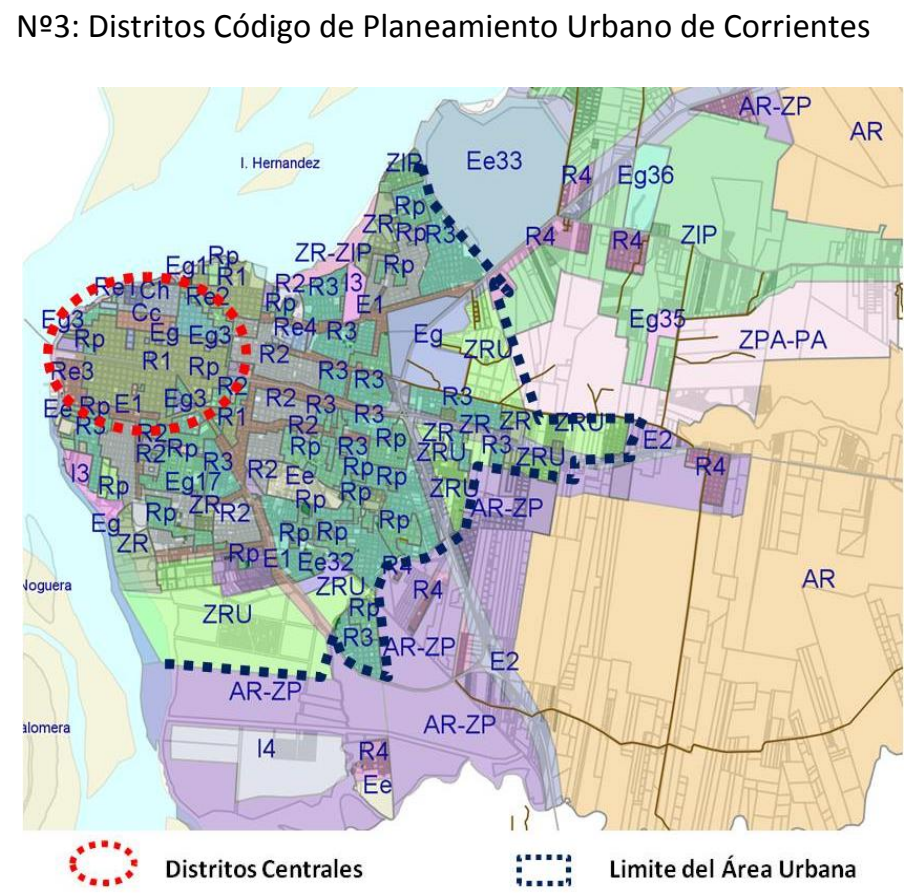

Fuente: Elaboración propia. SIG Municipalidad de Ctes.

A partir de dicha centralidad, limitada al norte y el oeste por el río Paraná, se desarrollan corredores viales primarios, con dispersión radial (hacia el sur y este), escasa conexión entre ellos y que atraviesan la red vial secundaria de la ciudad la cual presenta un bajo porcentaje de pavimentación.

En la corona más alejada del área central, la trama vial pierde consolidación y se visualiza dispersa, con baja conectividad y vinculada al centro sólo a través de la red vial principal. Cabe destacar, que desde los distritos centrales existe una única vía de vinculación, hacia el NO, con la ciudad de Resistencia a través del puente General Belgrano. (Imagen $N^{\circ} 4$ )

En relación directa con estas características de la estructura urbana y de la infraestructura, se distribuye el sistema de transporte y los recorridos del transporte público de pasajeros.

Se puede identificar un área con mayor cobertura, donde los recorridos forman una malla, con una fuerte coincidencia con el área central, a partir de allí y de manera concéntrica se observan áreas con espacios intersticiales mayores entre los recorridos que van aumentando hacia la periferia, y finalmente escasas líneas de servicios que conectan puntos pero sin relación entre sí. (Imagen №4)

Esta última situación obliga al usuario del transporte urbano a pasar por el centro toda vez que se moviliza desde un barrio periférico a otro de similar localización. Esto es aun más relevante para los denominados barrios "extraurbanos" del municipio de Corrientes, como el Perichon al norte, Laguna Brava y Barrio Cremonte al Este, y Barrio Dr. Montaña y Barrio Esperanza al sur.

Publicado en formato digital: Arq. Silvina López; Ing. Guillermo Antonio Arce. CONTRIBUCION DE LAS ENCUESTAS DE MOVILIDAD DOMICILIARIA AL ANALISIS DE LA MOVILIDAD URBANA. EOD APLICADA AL GRAN CORRIENTES.. Revista Geográfica Digital. IGUNNE. Facultad de Humanidades. UNNE. Año 12. № 24. Julio - Diciembre 2015. ISSN 1668 - 5180. Resistencia, Chaco. En: http://hum.unne.edu.ar/revistas/geoweb/default.htm 
Revista Geográfica Digital. IGUNNE. Facultad de Humanidades. UNNE. Año 12. № 24. Julio - Diciembre 2015. ISSN 1668-5180 Resistencia, Chaco

Similar situación se da en los procesos de movilidad hacia y desde la ciudad de Resistencia, que obliga a desplazarse utilizando el puente General Belgrano y la RN16, única vía que vincula ambas ciudades.

Imagen №4: Red vial y recorridos líneas de transporte público colectivo. Área Urbana de Corrientes

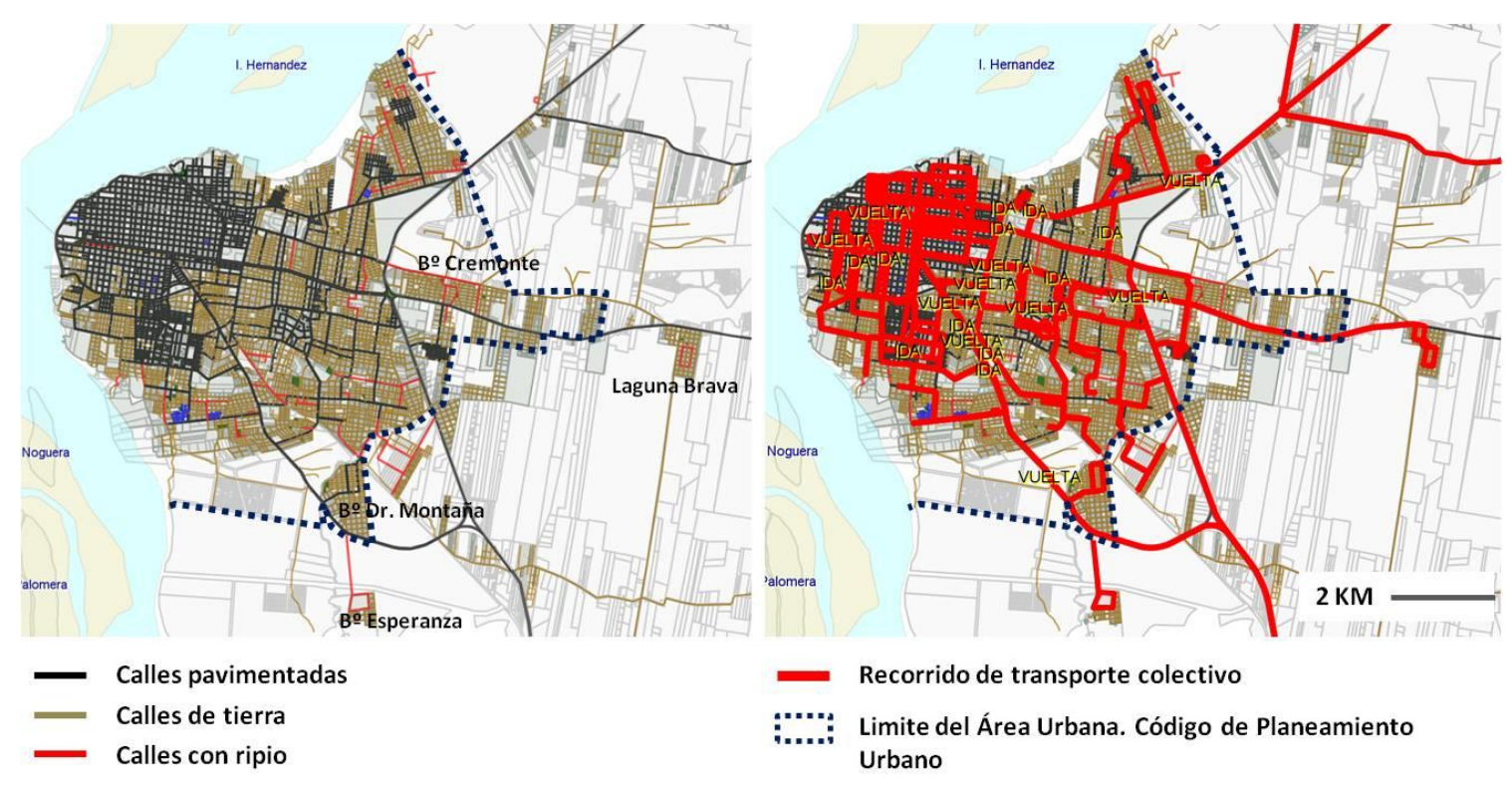

Fuente: Elaboración propia en base a SIG ciudad de Corrientes. 2015

En cuanto a las localidades de Riachuelo y Santa Ana, y las áreas periurbanas y rurales incluidas en el dominio "Resto de Corrientes", una característica común es que su red vial de circulación local (constituida por calles de tierra), se vincula en forma directa a la red principal (una ruta provincial o nacional pavimentada) que forma parte de la trama urbana y en la que no se ha desarrollado una red secundaria que haga de transición entre las anteriores.

Esta situación condiciona el recorrido del transporte público que circula sobre las vías pavimentadas con escaso o ningún acceso al interior de las localidades. Por otra parte, tiene mucha incidencia no sólo la distancia y la vía de acceso seleccionada para ingresar a la ciudad, sino también la frecuencia de los servicios.

Cabe reflexionar en relación con los barrios extra urbanos y localidades aledañas, que parte del recorrido se realiza sobre rutas nacionales o provinciales para después ingresar al ejido urbano de la capital, en donde la velocidad de transporte promedio es menor por el mayor número de paradas y detenciones por semáforos y la propia densidad vehicular de la ciudad.

En el caso de la localidad de Riachuelo cuenta con dos servicios, la Línea 101 C, que realiza el recorrido Cremonte - Ponce - Riachuelo - Puerto con una frecuencia de 35 minutos. Este recorrido

Publicado en formato digital: Arq. Silvina López; Ing. Guillermo Antonio Arce. CONTRIBUCION DE LAS ENCUESTAS DE MOVILIDAD DOMICILIARIA AL ANALISIS DE LA MOVILIDAD URBANA. EOD APLICADA AL GRAN CORRIENTES.. Revista Geográfica Digital. IGUNNE. Facultad de Humanidades. UNNE. Año 12. № 24. Julio - Diciembre 2015. ISSN 1668 - 5180. Resistencia, Chaco. En: http://hum.unne.edu.ar/revistas/geoweb/default.htm 
Revista Geográfica Digital. IGUNNE. Facultad de Humanidades. UNNE. Año 12. № 24. Julio - Diciembre 2015. ISSN 1668-5180 Resistencia, Chaco

se hace a través de la RN 12 e ingresando a la ciudad por la Av. Dr. Alfonsín. Y Además la línea 103 D - Riachuelo - Puerto con una frecuencia de 2 horas. Este recorrido se hace a través de la RN 12 e ingresando a la ciudad por la Av. Maipú (Imagen $\mathrm{N}^{\circ} 5$ )

En el caso de la localidad de Santa Ana también existen dos servicios, la Línea 11, que funciona en horarios limitados y con una frecuencia aproximada de 2 horas de lunes a viernes y de 2.30 horas los fines de semana y feriados. Este recorrido se hace a través de la RN 12 e ingresando a la ciudad por la Av. Libertad. Recientemente se habilito la Línea 109 A que realiza el recorrido $B^{\circ}$ Rio Paraná - Laguna Soto - Santa Ana, que llega a 2 kilómetros del pueblo. (Imagen N5)

La estructura de la ciudad, con una marcada centralización de servicios y la geometría radial de su red vial, así como la distribución de las actividades descriptas, condiciona fuertemente, la movilidad de las personas y la elección de los modos de transporte.

Imagen №5: Recorrido de líneas de transporte público colectivo a localidades del Gran Corrientes

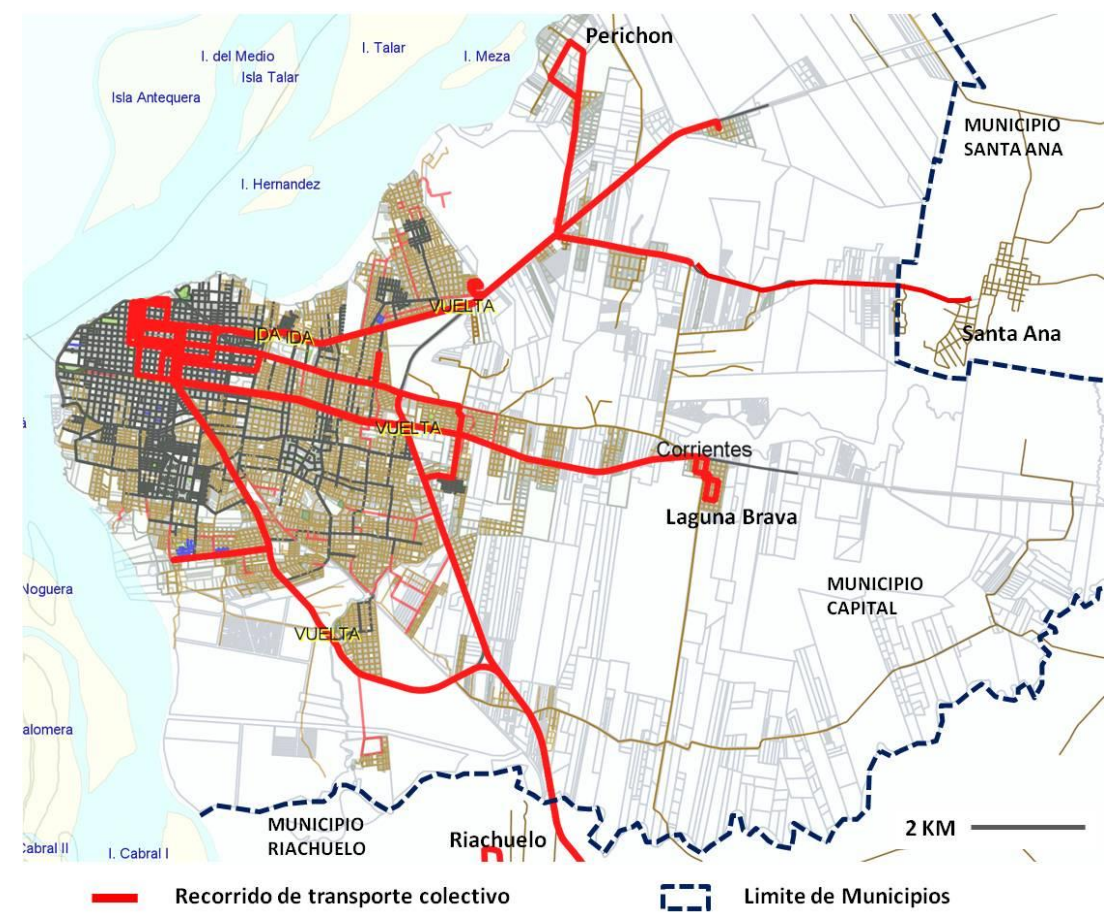

Fuente: Elaboración propia en base a SIG ciudad de Corrientes. 2015

\section{Observación a los Resultados de la EOD}

En este punto se realizan algunas observaciones a partir de la revisión de los resultados, en función del análisis de la metodología aplicada en este estudio, y considerando que información permite obtener la EOD.

Publicado en formato digital: Arq. Silvina López; Ing. Guillermo Antonio Arce. CONTRIBUCION DE LAS ENCUESTAS DE MOVILIDAD DOMICILIARIA AL ANALISIS DE LA MOVILIDAD URBANA. EOD APLICADA AL GRAN CORRIENTES.. Revista Geográfica Digital. IGUNNE. Facultad de Humanidades. UNNE. Año 12. № 24. Julio - Diciembre 2015. ISSN 1668 - 5180. Resistencia, Chaco. En: http://hum.unne.edu.ar/revistas/geoweb/default.htm 
Revista Geográfica Digital. IGUNNE. Facultad de Humanidades. UNNE. Año 12. № 24. Julio - Diciembre 2015. ISSN 1668-5180 Resistencia, Chaco

Los resultados de viajes

realizados por dominio, muestran un mayor porcentaje de viajes en el "Macrocentro" de Corrientes en relación con el "Resto de Corrientes", pero se trata de valores muy próximos, en el entorno del $60 \%$. (Tabla N²)

En relación con los medios de transporte por dominio, los medios más representativos en porcentaje son: en "colectivo", "a pie", en "ciclomotor" y en "auto conductor". Los porcentajes menos representativos corresponden a los demás medios considerados en la $E O D$, que son: bicicleta, tren, auto acompañante, taxi, remiss autorizado, remiss no autorizado, bus de la empresa, transporte escolar, otros.

En "Macrocentro" los medios que predominan es "a pie", "auto conductor" y "colectivo". El porcentaje de "colectivo" es marcadamente superior en "Resto de Corrientes", así como el de "automóvil conductor" es marcadamente inferior. Los valores de uso de "ciclomotor" son similares en ambos dominios. (Tabla №3)
Tabla №2: Viajes por dominio

\begin{tabular}{|l|c|c|c|}
\hline \multicolumn{1}{|c|}{ Dominio } & SI viaja & NO viaja & Total \\
\hline $\begin{array}{l}\text { MACROCENTRO } \\
\text { CORRIENTES }\end{array}$ & $61,00 \%$ & $39,00 \%$ & $100,00 \%$ \\
\hline $\begin{array}{l}\text { RESTODE } \\
\text { CORRIENTES }\end{array}$ & $57,40 \%$ & $42,60 \%$ & $100,00 \%$ \\
\hline
\end{tabular}

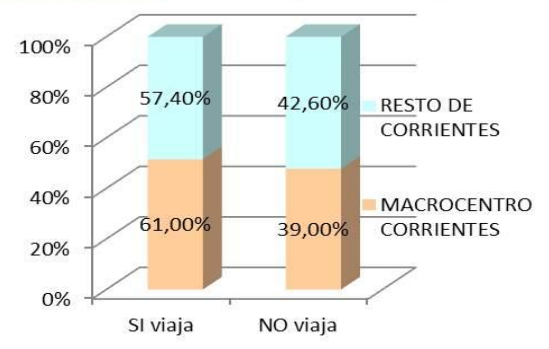

Tabla №3: Medios de transporte por dominio

\begin{tabular}{|l|c|c|c|c|c|c|}
\hline \multicolumn{1}{|c|}{ Dominio } & Colectivo & A pie & Ciclomotor & $\begin{array}{c}\text { Auto } \\
\text { conductor }\end{array}$ & Otros & Total \\
\hline $\begin{array}{l}\text { MACROCENTRO } \\
\text { CORRIENTES }\end{array}$ & $17,60 \%$ & $24,30 \%$ & $16,70 \%$ & $23,80 \%$ & $17,60 \%$ & $100 \%$ \\
\hline $\begin{array}{l}\text { RESTO DE } \\
\text { CORRIENTES }\end{array}$ & $35,00 \%$ & $22,70 \%$ & $19,00 \%$ & $11,10 \%$ & $12,20 \%$ & $100 \%$ \\
\hline
\end{tabular}

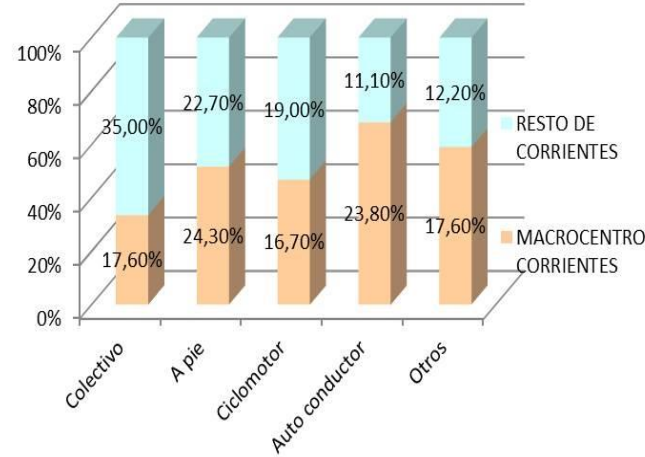

Fuente: elaboración propia en base a EOD.

Los resultados se pueden explicar también con los valores de tenencia de vehículos motorizados en los hogares (excluyendo ciclomotores), donde en el "Macrocentro" se da el porcentaje más alto. (Tabla №4).

Por otro lado, es interesante analizar los resultados de "usuarios frecuentes de colectivos" donde los porcentajes son muy significativos en ambos dominios, y el porcentaje de usuarios del “Macrocentro" (64,4\%) es levemente inferior al del "Resto de Corrientes". (Tabla №5)

Publicado en formato digital: Arq. Silvina López; Ing. Guillermo Antonio Arce. CONTRIBUCION DE LAS ENCUESTAS DE MOVILIDAD DOMICILIARIA AL ANALISIS DE LA MOVILIDAD URBANA. EOD APLICADA AL GRAN CORRIENTES.. Revista Geográfica Digital. IGUNNE. Facultad de Humanidades. UNNE. Año 12. № 24. Julio - Diciembre 2015. ISSN 1668 - 5180. Resistencia, Chaco. En: http://hum.unne.edu.ar/revistas/geoweb/default.htm 


\begin{tabular}{|l|l|}
\hline$G$ & $\begin{array}{l}\text { Revista Geográfica Digital. IGUNNE. Facultad de Humanidades. UNNE. Año 12. № } 24 . \\
\text { Julio - Diciembre 2015. ISSN 1668-5180 Resistencia, Chaco }\end{array}$ \\
\hline
\end{tabular}

Tabla №4: Tenencia de vehículos motorizados

\begin{tabular}{|l|c|c|c|}
\hline \multicolumn{1}{|c|}{ Dominio } & $\begin{array}{c}\text { SI tiene } \\
\text { vehículo } \\
\text { motorizado }\end{array}$ & $\begin{array}{c}\text { NO tiene } \\
\text { vehículo } \\
\text { motorizado }\end{array}$ & Total \\
\hline $\begin{array}{l}\text { MACROCENTRO } \\
\text { CORRIENTES }\end{array}$ & $38,70 \%$ & $61,30 \%$ & $100,00 \%$ \\
\hline $\begin{array}{l}\text { RESTO DE } \\
\text { CORRIENTES }\end{array}$ & $25,50 \%$ & $74,50 \%$ & $100,00 \%$ \\
\hline
\end{tabular}

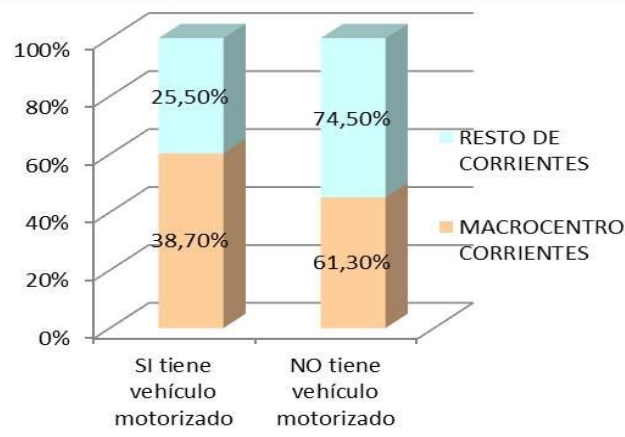

Tabla №5: Usuarios frecuentes de colectivos

\begin{tabular}{|l|c|c|c|}
\hline \multicolumn{1}{|c|}{ Dominio } & $\begin{array}{c}\text { SI es usuario } \\
\text { frecuente de } \\
\text { colectivo }\end{array}$ & $\begin{array}{c}\text { No es usuario } \\
\text { frecuente de } \\
\text { colectivo }\end{array}$ & Total \\
\hline $\begin{array}{l}\text { MACROCENTRO } \\
\text { CORRIENTES }\end{array}$ & $64,40 \%$ & $35,60 \%$ & $100,00 \%$ \\
\hline $\begin{array}{l}\text { RESTODE } \\
\text { CORRIENTES }\end{array}$ & $72,90 \%$ & $27,10 \%$ & $100,00 \%$ \\
\hline
\end{tabular}

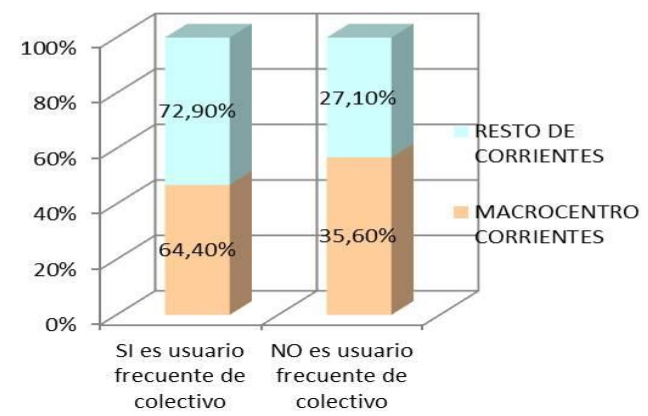

Fuente: Elaboración propia en base a EOD

En cuanto a motivos del viaje, "Hogar", "lugar de trabajo" y "lugar de estudio" son las actividades con mayor porcentaje en el destino de viaje en ambos dominios, y en general se observan valores muy similares en los destinos de viaje en ambos dominios.

Tabla №6: Actividad en el destino del viaje por dominio

\begin{tabular}{|l|c|c|c|c|c|c|}
\hline \multicolumn{1}{|c|}{ Dominio } & Hogar & Trabajo & Estudios & Compras & Otros & Total \\
\hline $\begin{array}{l}\text { MACROCENTRO } \\
\text { CORRIENTES }\end{array}$ & $48,70 \%$ & $24,20 \%$ & $15,50 \%$ & $2,80 \%$ & $8,80 \%$ & $100 \%$ \\
\hline $\begin{array}{l}\text { RESTODE } \\
\text { CORRIENTES }\end{array}$ & $48,30 \%$ & $21,80 \%$ & $15,80 \%$ & $2,50 \%$ & $11,60 \%$ & $100 \%$ \\
\hline
\end{tabular}

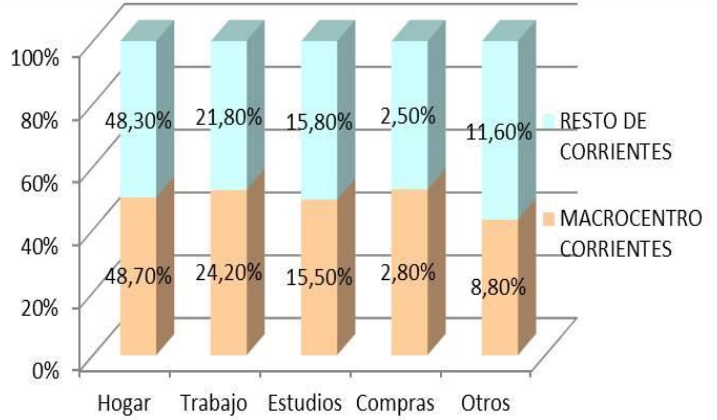

Fuente: Elaboración propia en base a EOD

La actividad "Compras" y los demás motivos que se agruparon en "otros" (asunto laboral, dejar o acompañar a centro educativo, salud, social, familia, deportes y recreación, trámite personal, ir a buscar empleo, pagos/bancos, etc.) presentan muy bajos porcentajes. (Tabla $\mathrm{N}^{\circ} 6$ )

Publicado en formato digital: Arq. Silvina López; Ing. Guillermo Antonio Arce. CONTRIBUCION DE LAS ENCUESTAS DE MOVILIDAD DOMICILIARIA AL ANALISIS DE LA MOVILIDAD URBANA. EOD APLICADA AL GRAN CORRIENTES.. Revista Geográfica Digital. IGUNNE. Facultad de Humanidades. UNNE. Año 12. № 24. Julio - Diciembre 2015. ISSN 1668 - 5180. Resistencia, Chaco. En: http://hum.unne.edu.ar/revistas/geoweb/default.htm 
Revista Geográfica Digital. IGUNNE. Facultad de Humanidades. UNNE. Año 12. № 24. Julio - Diciembre 2015. ISSN 1668-5180 Resistencia, Chaco

Con respecto al movimiento en los dominios, la primera observación es que el movimiento dentro del "Macrocentro" es superior al movimiento dentro de "Resto de Corrientes", o sea se producen más viajes en el primer caso.

En cuanto al movimiento entre dominios, es levemente superior desde "Macrocentro" a "Resto de Corrientes" que el movimiento inverso, es decir del "Resto de Corrientes" al "Macrocentro". (Tabla N7).

En el caso del movimiento entre dominios es imposible discriminar los que se realizan desde los barrios de la ciudad, de los que se realizan desde las localidades próximas, agrupados ambos en "Resto de Corrientes". Lo mismo ocurre con el movimiento desde el "Macrocentro" hacia los barrios y hacia las localidades próximas.

En relación con los datos de los movimientos entre dominios, se puede concluir que el resultado es poco representativo, debido justamente a la delimitación de los dominios realizada por el estudio que se ha analizado anteriormente.

Tabla №7: Movimiento entre dominios

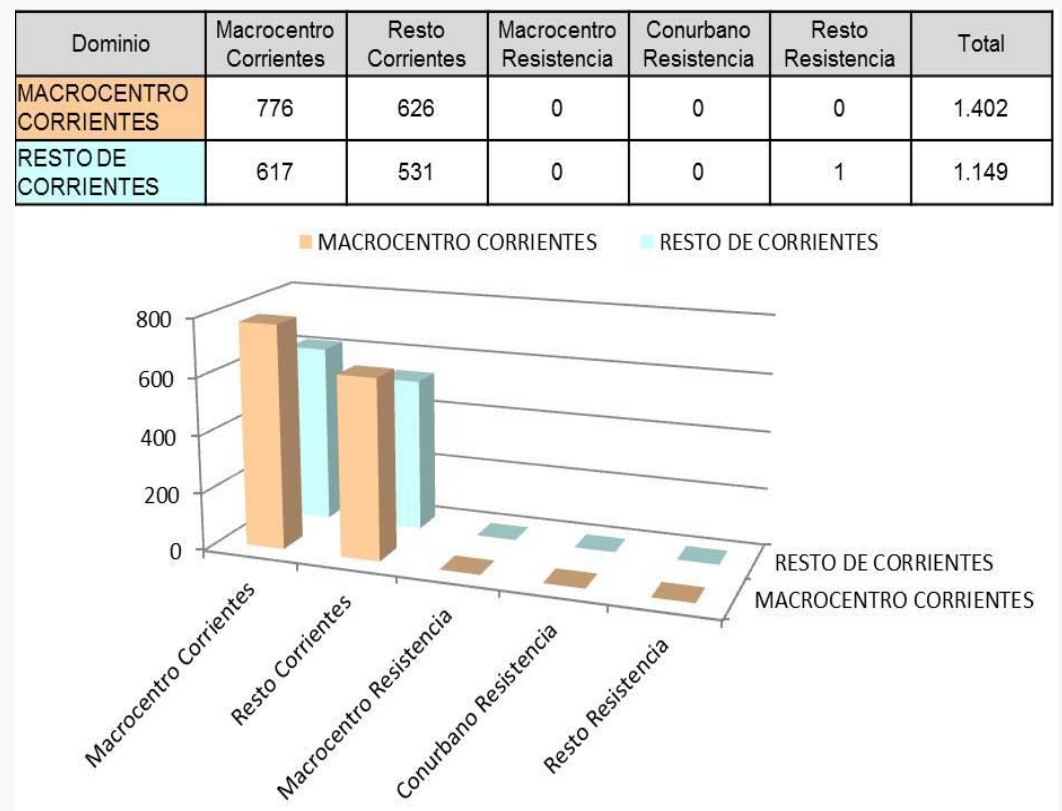

Fuente: elaboración propia en base a EOD

Otra cuestión que llama la atención, es que aparece sólo un caso de movimiento entre las ciudades de Corrientes y Resistencia, lo que no refleja el gran movimiento diario de pasajeros debido al intercambio comercial, educativo y administrativo entre las dos ciudades. Sobre todo si se considera que el servicio interurbano es prestado por dos empresas de transporte - TICSA y ATACO

Publicado en formato digital: Arq. Silvina López; Ing. Guillermo Antonio Arce. CONTRIBUCION DE LAS ENCUESTAS DE MOVILIDAD DOMICILIARIA AL ANALISIS DE LA MOVILIDAD URBANA. EOD APLICADA AL GRAN CORRIENTES.. Revista Geográfica Digital. IGUNNE. Facultad de Humanidades. UNNE. Año 12. № 24. Julio - Diciembre 2015. ISSN 1668 - 5180. Resistencia, Chaco. En: http://hum.unne.edu.ar/revistas/geoweb/default.htm 
Revista Geográfica Digital. IGUNNE. Facultad de Humanidades. UNNE. Año 12. № 24. Julio - Diciembre 2015. ISSN 1668-5180 Resistencia, Chaco

NORTE - que cuentan con vehículos con capacidad para 40 personas y con una frecuencia de entre 15-20 minutos. Además existen cuatro empresas de remises (dos de Resistencia y dos de Corrientes) que ofrecen el mismo servicio.

Teniendo en cuenta que en la EOD han sido consideradas las dos áreas metropolitanas, es difícil de entender por qué no fue una condicionante en el diseño metodológico el análisis de la movilidad entre ambas.

El tiempo de viaje promedio es mayor en el dominio "Macrocentro". Esto se podría explicar en los modos de viaje que predominan en este dominio, donde "a pie", y "auto conductor", representan casi el $50 \%$ del movimiento. En el primer caso el tiempo se relaciona con la distancia a recorrer, y en el segundo a la congestión del área central que genera demora en el traslado. (Tabla $\mathrm{N}^{\circ} 8$ )

Tabla №8: Duración promedio del viaje

\begin{tabular}{|c|c|c|}
\hline Dominio & Media & № Viajes \\
\hline $\begin{array}{c}\text { MACROCENTRO } \\
\text { CORRIENTES }\end{array}$ & $15: 15$ & 731 \\
\hline $\begin{array}{c}\text { RESTO DE } \\
\text { CORRIENTES }\end{array}$ & $11: 33$ & 3.344 \\
\hline
\end{tabular}

Fuente: Elaboración propia en base a EOD

La media del dominio "Resto de Corrientes" es menor a la de "Macrocentro" y llama mucho la atención considerando la variabilidad de las distancias de los puntos que componen el dominio, y que un alto porcentaje de los movimientos se realizaron desde y hacia "Macrocentro" de Corrientes, por lo que se estaría promediando el tiempo de viaje de puntos muy cercanos al con otros muy alejados, como el caso de las localidades de Santa Ana y Riachuelo.

Por otra parte, en los resultados de "medios de transporte por dominio" se observa que el $35 \%$ de los movimientos del dominio se realizó por medio de transporte colectivo, y el movimiento en "auto conductor" es muy poco significativo $(11,1 \%)$, por lo que el tiempo de 11:33 parece no corresponder a la situación real.

Se hace evidente que debido a la delimitación de los dominios realizada para el estudio, el tiempo promedio de viaje puede estar distorsionado. Para realizar un análisis aproximado de la situación real, sería necesario diferenciar las localidades que para el estudio fueron consideradas dentro del dominio "Resto de Corrientes" y que en realidad no lo son, del área que realmente correspondería considerar, que es el área urbana de la ciudad excluyendo el "Macrocentro".

En los resultados del estudio aparecen abundantes datos relacionados con las características socio-económicas de la población.

En cuanto a los niveles de ingreso total familiar, los más altos se dan en el "Macrocentro", más del $45 \%$ en el rango superior, mientras que en el "Resto de Corrientes" los porcentajes más significativos aparecen en los rangos inferiores.

Publicado en formato digital: Arq. Silvina López; Ing. Guillermo Antonio Arce. CONTRIBUCION DE LAS ENCUESTAS DE MOVILIDAD DOMICILIARIA AL ANALISIS DE LA MOVILIDAD URBANA. EOD APLICADA AL GRAN CORRIENTES.. Revista Geográfica Digital. IGUNNE. Facultad de Humanidades. UNNE. Año 12. № 24. Julio - Diciembre 2015. ISSN 1668 - 5180. Resistencia, Chaco. En: http://hum.unne.edu.ar/revistas/geoweb/default.htm 
Revista Geográfica Digital. IGUNNE. Facultad de Humanidades. UNNE. Año 12. № 24. Julio - Diciembre 2015. ISSN 1668-5180 Resistencia, Chaco

En relación con el ámbito laboral, en ambos dominios los porcentajes más altos se dan en "actividad privada" y "Estado", y en el "Macrocentro" se dan los mayores valores de trabajadores en el ámbito estatal. También aparecen los datos de los hogares que reciben planes sociales, con muy bajo porcentajes en el "Macrocentro" y el valor más alto (19\%) en el Resto de Corrientes.

La disponibilidad de transporte motorizado puede ser considerada un factor asociado al nivel de ingreso, y en ese sentido, como se vio anteriormente en los resultados de tenencia de vehículos motorizados en los hogares, en el "Macrocentro" se dan los valores más altos.

En relación con el planteo de que la movilidad aumenta con el aumento del ingreso, en este caso, en general no se observan grandes diferencias entre los dominios. Esto se puede deber al tipo de estratificación que se adoptó en el estudio, que no logra reflejar las particularidades de los grupos socioeconómicos en general, y en consecuencia no permite identificar sus hábitos de movilidad.

\section{Consideraciones finales}

Considerando que la finalidad principal del estudio EOD fue identificar la estructura y los patrones de movilidad como insumo para la planificación del transporte, es fundamental el criterio utilizado para la definición de las zonas o dominios del estudio, ya que la zonificación implica la homogenización de determinadas áreas de la ciudad y por lo tanto condiciona el análisis de la movilidad en y entre ellas. Seguí Pons, incluso indica que la precisión de los resultados depende de correcta realización de esta tarea.

Con respecto a lo anterior, si bien se considera que el área definida como "Macrocentro" tiene buena correlación con la realidad, puede identificarse una gran discrepancia entre la estructura y conformación del territorio con la definición del dominio "Resto de Corrientes".

El criterio que se utilizó para la zonificación del Gran Corrientes, uniforma en el dominio "Resto Gran Corrientes" toda el área urbana de la ciudad (excepto Macrocentro), las zonas rurales y las localidades de los municipios contiguos. Esta homogenización no representa la realidad territorial, ya que unifica espacios con marcadas diferencias estructurales y funcionales y no respeta las definiciones metodológicas del mismo estudio.

La potencialidad que tiene la aplicación de la EOD se centra particularmente en la posibilidad de encontrar parámetros relevantes en términos de planificación para los organismos interesados en la misma. En este sentido, y recuperando lo que Vasconcellos plantea sobre la necesidad de comprender la estructura de la ciudad para comprender qué desplazamientos se realizan, fue posible observar la relación entre la estructura concéntrica de la ciudad, con escasa consolidación de la trama vial urbana, sobre la que se instala el sistema de trasporte, y la movilidad de las personas y la elección de los modos de transporte.

Otro aspecto a destacar es la circulación del transporte público entre la ciudad de Corrientes y los municipios aledaños, que se restringe fuertemente a la circulación por la red vial primaria. Esto

Publicado en formato digital: Arq. Silvina López; Ing. Guillermo Antonio Arce. CONTRIBUCION DE LAS ENCUESTAS DE MOVILIDAD DOMICILIARIA AL ANALISIS DE LA MOVILIDAD URBANA. EOD APLICADA AL GRAN CORRIENTES.. Revista Geográfica Digital. IGUNNE. Facultad de Humanidades. UNNE. Año 12. № 24. Julio - Diciembre 2015. ISSN 1668 - 5180. Resistencia, Chaco. En: http://hum.unne.edu.ar/revistas/geoweb/default.htm 
permite identificar al menos dos problemas: la localización de paradas de colectivos a la vera de la ruta, en la propia banquina, lo cual es un riesgo para la circulación vehicular y los propios usuarios del transporte, y el otro problema es la situación que Begag (1988) identifica como "movilidad forzada" pues obliga a los usuarios a desplazarse hacia la ruta para acceder al transporte público

En cuanto a los resultados, se analizaron en forma parcial con grandes limitaciones. Por un lado, no fue posible discriminar tiempo medio según zona de residencia, ya que la delimitación de los dominios no refleja las distintas zonas residenciales como ya se ha explicado en el análisis. Otro problema relacionado con ello es que se promedian tiempos y recorridos en zonas rurales y urbanas en el dominio "Resto de Corrientes", lo que puede traer aparejado distorsiones de los resultados al momento de toma de decisiones con vistas a la planificación u ordenamiento.

El estudio no permite identificar los hábitos de movilidad de los grupos socioeconómicos en general, ya que en los resultados obtenidos no se dan grandes diferencias entre los dominios. En este sentido, es importante considerar que los datos que se pueden obtener de la EOD permitirá lograr una aproximación a los hábitos distintivos de cada grupo socioeconómico en el uso del transporte sólo si se logra reflejar las particularidades de la población.

Finalmente, es necesario tener en cuenta las limitaciones de los estudios de transporte que se enfocan en el viaje realizado, ya que este es sólo una manifestación parcial de la movilidad que no incluye los aspectos subjetivos y objetivos, materiales e inmateriales, materializables $\mathrm{y}$ materializados ligados al mismo. El viaje realizado es la manifestación de los desplazamientos hechos con las redes y servicios de transporte disponibles, con la organización y uso del suelo disponible, y no es una revelación de los desplazamientos en sí.

Aparecen como necesarias nuevas formas de gestión de la movilidad que apunten a integrar la planificación urbana y del transporte en los ámbitos de los gobiernos locales, y en ese marco, los estudios de movilidad apropiados, serán aquellos que consideren el universo de viajes de la movilidad concebida, de la movilidad efectiva y de la movilidad realizada, arrojando resultados que permitan lograr una aproximación a la situación real de la movilidad.

\section{Bibliografía}

ALCANTARA VASCONCELLOS, E (2010). Análisis de la movilidad urbana. Espacio, medio ambiente y equidad. CAF. Bogotá, Colombia. ISBN: 978-980-6810-60-0

ARCE, G, LOPEZ, S. Y ALBERTO, J. (2013). “Propuesta de geoindicadores en desarrollo sostenible en espacios periurbanos. Estudio de caso en la ciudad de Corrientes". Anales del XXXIII Encuentro de Geohistoria Regional. Pp.251- 268. Universidad Nacional de Formosa. EDUNaF. (CD ROOM) ISBN 978-987-1604-21-0.

CARDOZO, O., GOMEZ, E. y PARRAS, M. (2009). Teoría de Grafos y Sistemas de Información Geográfica aplicados al Transporte Público de Pasajeros en Resistencia (Argentina). Revista Transporte y Territorio № 1, Universidad de Buenos Aires, 2009. ISSN: 1852-7175. pp. 89-111.

CF I y Gobierno de Corrientes (2008). Plan estratégico de desarrollo Urbano Ambiental de la Provincia de Corrientes. P.E. D. U. A. C. Informe Final TOMO III.

Publicado en formato digital: Arq. Silvina López; Ing. Guillermo Antonio Arce. CONTRIBUCION DE LAS ENCUESTAS DE MOVILIDAD DOMICILIARIA AL ANALISIS DE LA MOVILIDAD URBANA. EOD APLICADA AL GRAN CORRIENTES.. Revista Geográfica Digital. IGUNNE. Facultad de Humanidades. UNNE. Año 12. № 24. Julio - Diciembre 2015. ISSN 1668 - 5180. Resistencia, Chaco. En: http://hum.unne.edu.ar/revistas/geoweb/default.htm 
Revista Geográfica Digital. IGUNNE. Facultad de Humanidades. UNNE. Año 12. № 24. Julio - Diciembre 2015. ISSN 1668-5180 Resistencia, Chaco

GUTIERREZ, A. (2012). ¿Qué es la movilidad? Elementos para (re) construir las definiciones básicas del campo del transporte. Bitacora 21 (julio-diciembre 2012). Universidad Nacional de Colombia, Bogotá

GUTIERREZ, A. (2009) "La movilidad de la metrópolis desigual: el viaje a la salud pública y gratuita en la periferia de Buenos Aires", en: EGAL, 17 págs. Montevideo. www.egal2009.com

GUTIERREZ, A. (2010) "Movilidad, transporte y acceso: una renovación aplicada al ordenamiento territorial", en: Scripta Nova, Vol. XIV, N331 (86), 16 págs. http://www.ub.es/geocrit/sn/sn-331/sn-331-86.htm

LOPEZ, S, ARCE, G., ALBERTO, J. (2014). "Indicadores de desarrollo sostenible para espacios sujetos a la presión del crecimiento urbano. Santa Ana de los Guácaras. Corrientes". XXXIV de Geohistoria Regional. Resistencia, 26 de septiembre de 2014. En prensa.

PIZARRO, A. (2013). Políticas integradas y sostenibles de movilidad: revisión y propuesta de un marco conceptual. Boletín FAL. Edición $\mathrm{N}$ ㅇ 323 № 7, 2013.

SANZ ALDUAN, A. (2012). Síntesis del documento "La movilidad sostenible en la planificación urbanística y territorial”. Grupo de Estudios y Alternativas (gea21 S.L.). En; www.promotionsarriguren.es

SCORNIK, C. y OTROS. (2012). Consideraciones sobre el proceso de metropolización del Gran Corrientes-Gran Resistencia. IPUR. FAU.UNNE. Cuaderno Urbano №13. Resistencia jul./dic. 2012

SEGUI PONS, J. (1991). Geografía de redes y sistemas de transporte. Ed. Síntesis. España.

\section{Otras Fuentes}

CÓDIGO DE PLANEAMIENTO URBANO DE LA CIUDAD DE CORRIENTES Ordenanza № 1071/88. Segundo texto actualizado y ordenado al 31/03/13.

ENCUESTAS DE MOVILIDAD DOMICILIARIA Origen - Destino para las Áreas Metropolitanas de las ciudades de Resistencia - Corrientes. PTUMA. 2013. Proyecto de Transporte Urbano en Áreas Metropolitanas de la Argentina. Ministerio del Interior y Transporte. Préstamo 7794 BIRF. Informe Final.

PLAN ESTRATEGICO TERRITORIAL Avance II. 2011. Ministerio de Planificación Federal, Inversión Pública y Servicios.

SIG Ciudad de Corrientes. Secretaría de Planeamiento. Municipalidad de la Ciudad de Corrientes En: http://gis.ciudaddecorrientes.gob.ar/gis/gis publico.phtml. Consulta agosto 2015

Publicado en formato digital: Arq. Silvina López; Ing. Guillermo Antonio Arce. CONTRIBUCION DE LAS ENCUESTAS DE MOVILIDAD DOMICILIARIA AL ANALISIS DE LA MOVILIDAD URBANA. EOD APLICADA AL GRAN CORRIENTES.. Revista Geográfica Digital. IGUNNE. Facultad de Humanidades. UNNE. Año 12. № 24. Julio - Diciembre 2015. ISSN 1668 - 5180. Resistencia, Chaco. En: http://hum.unne.edu.ar/revistas/geoweb/default.htm 